\title{
Medicina baseada em evidência x psicanálise baseada na ex-sistência
}

\author{
Soraya Carvalho
}

Em um mundo orientado pelo discurso capitalista, onde o sofrimento é, muitas vezes, uma mercadoria, responsável pela geração de novos bens de consumo, qual o lugar da psicanálise? Como não ceder da ética do bem-dizer do real, que lhe é própria, ao imperativo do bem-estar da lógica do capital? Enfim, como os analistas devem se situar no discurso do seu tempo sem sucumbir às demandas impostas pela política desse discurso? O que a psicanálise tem a ver com isso? Dentro de um contexto em que o sucesso é contabilizado pela mais-valia dos resultados e dos objetos, em que a visada da cura se restringe a psicoterapias breves e eficazes, isso constitui um problema crucial para a psicanálise visto que, como frisou Lacan em A Terceira (1974a/2002, p. 49), ela não tem sucesso por não livrar o falasser do sintoma nem do real?

\section{Medicina baseada em evidências - MBE}

O modelo biotecnicista da medicina contemporânea adota como regra a eficácia do tratamento, critério fundamentado em uma metodologia denominada de medicina baseada em evidências (MBE). Derivada da epidemiologia clínica anglo-saxônica, a MBE surgiu na década de 90, com o propósito de diminuir a distância entre o conhecimento científico e sua aplicação clínica. Em linhas gerais, a MBE pretende objetivar a medicina, ao modo positivista, por meio do estudo de procedimentos utilizados na prática médica, dos quais extrai informações de eficácias diagnósticas e terapêuticas já comprovadas em estudos publicados, submetendo-os a tratamentos estatísticos e gerando guidelines ou manuais de apoio a decisões diagnósticas (NOVAES, 1999).

\section{Evidências}

A ambição de objetividade no conhecimento científico fez de Descartes um dos precursores da ciência moderna. Seus pressupostos e regras criados há 400 anos continuam influenciando o modo de conceber a ciência na atualidade. Em seu 
Discurso do método, Descartes desenvolveu alguns princípios, dentre eles, o princípio das evidências, segundo o qual, evidências são as "ideias claras e distintas", aquelas igualmente concebidas por todos, independentemente dos sentidos. Dessa maneira, ele elaborou a regra da evidência, que considera verdadeiro apenas o que é evidente, tornando a evidência o ideal de exatidão da ciência (GERBASE, 2008, pp.9-15).

Fundamentada na lógica cartesiana, a MBE postula que para um método ser eficaz e científico, suas ideias têm que ser evidentes. Que evidências científicas podem comprovar a eficácia do método da associação livre ou os conceitos psicanalíticos de inconsciente, desejo, real, sintoma, gozo? A psicanálise pode ser avaliada a partir desse critério?

A eficácia de uma terapêutica também pode ser medida pela sua capacidade de fazer o sujeito retornar o mais rapidamente possível ao trabalho. Por essa perspectiva, é possível afirmar que este é um critério determinado pelas leis de mercado; portanto, norteado pelo discurso capitalista, e a psicanálise, por sua vez, não está imune aos efeitos produzidos por essas leis. Isso quer dizer que, se a eficácia é medida por parâmetros objetivos, replicáveis e transmissíveis, o método psicanalítico vem sendo considerado ineficaz por gerar resultados desprovidos de evidências, tornando-se, por isso, alvo de duras críticas. Críticas que ecoam nos diversos contextos clínicos em que a psicanálise é frequentemente contraindicada para o tratamento de diversas sintomatologias. Embora não existam estudos que comprovem sua ineficácia, considerá-la obsoleta virou uma regra, uma verdadeira (e)vidência científica.

\section{A psicanálise é uma ciência?}

A preocupação de incluir a psicanálise no escopo da ciência está presente em Freud desde o seu Projeto para uma psicologia científica, de 1895: "a finalidade deste projeto é estruturar uma psicologia que seja uma ciência natural [...]" (FREUD, 1895/1996, p. 395). Ao longo de sua obra, Freud tentou dar a prova da cientificidade da psicanálise por meio da metodologia de investigação dos processos psíquicos. Ele compreendia a psicanálise como uma ciência, ou para ser mais preciso, como uma Ciência da Natureza, Naturwissenchaft (FREUD, 1933/1996), como a Química, a Física, a Fisiologia, (FREUD, 1940/1996, p. 227), na qual o indivíduo pode representar toda a classe à qual pertence por conter em si todas as características da sua espécie, diferentemente da Ciência do Espírito, Geisteswissenschaft, na qual cada objeto tem individualidade própria não dedutível a uma classe. Desta forma, enquanto as Ciências do Espírito estavam sujeitas a interpretações baseadas em juízos de valor, as Ciências da Natureza baseavam-se em um juízo da realidade e propunham a reflexão neutra e racional dos dados coletados (MEZAN, 2007).

Com Lacan não é diferente. De acordo com seu artigo Respostas a estudantes de filosofia (1966b/2003, p. 218), uma ciência é definida pelo seu objeto, e "o objeto da psicanálise não é o homem; é aquilo que lhe falta - não uma falta absoluta, mas a fal- 
ta de um objeto...". O objeto da psicanálise é o objeto $a$, produto da divisão do sujeito (LACAN, 1965/1998, p. 877), que, por sua vez, é produto da divisão significante.

Por outro lado, ao admitir a existência do inconsciente, a psicanálise provocou uma subversão no cogito cartesiano, deslocando a supremacia do sujeito da razão, do "penso, logo sou", para o sujeito do inconsciente, do "penso, lá onde não sou” ou "sou, lá onde não penso".

Em A ciência e a verdade, vemos Lacan afirmar que, por mais paradoxal que possa parecer, o sujeito da psicanálise é o mesmo sujeito da ciência; isto porque, seja na ciência ou na psicanálise, a verdade se coloca como causa, e o saber, posto em prática (LACAN, 1965/1998, p. 884). Entretanto, da verdade como causa, a ciência não "quer-saber-nada", o que Lacan identificou como a Verwerfung da ciência (Ibid., p. 889), simplesmente porque nela, "[...] a verdade [...]deve ser reconhecida sob o aspecto da causa formal", enquanto que “[...] a psicanálise acentua seu aspecto de causa material”. Essa causa material é o significante, justamente o que deve qualificar a originalidade da psicanálise na ciência (Ibid., p.890).

Em um dos seus últimos seminários, o Livro 24, Lacan (1976-77, inédito) reavaliou a relação da psicanálise com a ciência:

A psicanálise não é uma ciência. Não tem estatuto de ciência, não pode senão aguardá-lo, esperá-lo. É um delírio - um delírio do qual se aguarda que traga uma ciência. Podemos esperar muito tempo! Não há progresso, e o que se espera não é necessariamente o que se recolhe. É um delírio científico, mas isso não quer dizer que jamais a prática analítica trará uma ciência. Esta ciência tem tanto menos chances de amadurecer quanto é antinômica e que, pelo uso que fazemos dela, sabemos que há relações entre a ciência e a lógica.

Retoma a questão no seminário seguinte, O momento de concluir (LACAN, 1977-78/inédito):

O que tenho a lhes dizer, é que a psicanálise é para ser levada a sério, apesar de que não é uma ciência. Não é mesmo uma ciência de jeito nenhum. Pois, o mais enfadonho, como mostrou superabundantemente o assim chamado Karl Popper, não é uma ciência porque é irrefutável. É uma prática, uma prática que durará o que durar. É uma prática de tagarelice.

E Lacan (1974b/2004) chega a afirmar em entrevista a Emilio Granzotto: que "a única ciência verdadeira, séria, a ser seguida é a ficção científica”, pois a ciência oficial, em cujos laboratórios estão seus altares, avança às cegas. Propõe, ain- 
da, acrescentar às três tarefas impossíveis citadas por Freud - governar, educar e exercer a psicanálise - uma quarta, a ciência. E sobre a psicanálise, complementa:

Eu a defino como sintoma - revelador do mal-estar da civilização na qual vivemos. Certo, não é uma filosofia. [...] A psicanálise também não é uma fé, e não me agrada chamá-la de ciência. Digamos que é uma prática e que ela se ocupa do que não está funcionando. Terrivelmente difícil porque ela pretende introduzir na vida do dia a dia o impossível, o imaginário. Ela obteve alguns resultados até o presente, mas ainda não tem regras e se presta a toda sorte de equívocos.

A ciência, tanto quanto a psicanálise, visa a um saber no real. A diferença é que na psicanálise, enquanto o real em questão diz respeito ao $a$-sexo, ao que não se escreve, isto é, à impossibilidade da relação; na ciência, o real em jogo aponta para um saber que se escreve e que rejeita as singularidades (SOLER, 2009, p. 187). Portanto, o Discurso da Ciência não apenas foraclui o sujeito, mas também a verdade na medida em que a verdade não é a exatidão, mas o singular.

Em suma, ainda que a psicanálise e a ciência se ocupem com o real: ali onde a ciência propõe a consciência, a psicanálise apresenta o inconsciente; onde a ciência só admite a certeza, a psicanálise responde com a dúvida; onde a ciência foraclui o sujeito, a psicanálise o presentifica em sua divisão e falta; onde a ciência propõe um saber completo, a psicanálise aponta para um saber não todo; e ali onde a ciência se empenha em uma obstinada busca da verdade absoluta, a psicanálise denuncia a verdade mentirosa.

\section{A psicanálise baseada na ex-sistência - PBEx}

A MBE defende que a medicina deve buscar objetividade e respaldo científico, orientando suas ações por evidências, quer dizer, por "verdades científicas", extraídas do estudo de práticas bem-sucedidas submetidas a generalizações. Em outras palavras, a clínica do um é determinada pela lógica do todo. Contrariamente, a psicanálise se orienta pela lógica do um a um, pela especificidade do falasser. E, se a ideia do inconsciente pode ser generalizada, é pelo fato de que ele está posto para todos, mas a forma como cada um se serve dele é particular.

$O$ ideal de cientificidade na medicina não somente exclui o sujeito que sofre, não levando em conta sua participação na formação do seu sintoma, como também aquele que o trata. A clínica psicanalítica, por sua vez, considera os efeitos do significante no corpo, bem como a responsabilidade do sujeito pelo seu sofrimento, e a do analista, pela condução ética da transferência no tratamento.

A descoberta do inconsciente levou Freud à criação de um método de cura pela palavra, a talking cure, mas apesar de todos os seus esforços, ele não conseguiu de- 
monstrar "cientificamente" a eficácia do seu método nem de sua teoria. Lacan tomou para si esta tarefa: para saber se a psicanálise funciona, é necessário, antes, saber o que é o homem. O homem ou falasser tem uma estrutura de linguagem, e "a estrutura é o real que vem à luz na linguagem" (LACAN, 1972/2003, p. 477). Isso quer dizer que, se o inconsciente é estruturado como uma linguagem, a linguagem é a estrutura e o falasser está submetido aos seus efeitos. Se estrutura quer dizer linguagem e a estrutura se inscreve no real, o real é um efeito de discurso (LACAN, 1966c/2003, p. 231). Por isso, para a psicanálise, a estrutura se engancha no ponto em que o simbólico e o imaginário tomam corpo. Se o corpo é um efeito de linguagem e se a linguagem é a estrutura, a estrutura é o efeito da linguagem sobre o corpo.

O homem não pensa com a alma, ele pensa porque uma estrutura, a de linguagem, recorta o seu corpo, corpo que nada tem a ver com a anatomia, como a histérica o testemunha; essa cisalha chega à alma com o sintoma obsessivo: pensamento com o qual a alma fica embaraçada, não sabe o que fazer (LACAN, 1973a/2003, p. 511).

No Seminário 21, Lacan defendeu a tese de que "há saber no real", e o saber no real está na ex-sistência, porque ele "insiste de fora e é perturbador" (LACAN, 1973-74/2016, p. 235). Complementou, ainda, que "[...] o inconsciente é alguma coisa no real" (Ibid., p. 237). Se a ciência e a psicanálise estão em busca da verdade e no discurso analítico a verdade está no lugar do saber, saber que é furado, inconsciente, real, para a psicanálise, a verdade é não toda. Em 1976, no Prefácio à edição inglesa do Seminário 11, Lacan concluiu que "se a psicanálise ex-siste, o inconsciente é o real” (LACAN, 1976/2003, p. 567). E é na experiência analítica, experiência estruturada como um discurso que se faz pela escrita, "[...] é apenas aí, que alguma coisa pode testemunhar o real" (LACAN, 1973-74/2016, p. 237), real que só se pode ter acesso pela letra (LACAN, 1974a/2002, p. 68).

Ora, dizer que "há saber no real" significa que há um saber não articulado, inconsciente, puramente significante, que quando articulado a outro significante pode produzir um sentido equivocado, e isso faz sintomas. O sintoma, para a psicanálise, é uma formação do inconsciente, portanto, uma formação de significantes, razão pela qual a realidade não participa da sua formação (GERBASE, 2011, p. 19). A matriz sintomática depende de um encontro do real, ou, mais precisamente, de um encontro contingente com um significante de alíngua. O desencadeamento do sintoma resulta de um encontro com algo impossível de ser dito e que convoca o saber de alíngua. Enquanto ser de linguagem, o falasser se embaraça diante da falta de um significante que nomeie o Outro gozo, o real, que se inscreve no que Lacan denominou de ex-sistência. Para fazer suplência a essa falta, o sujeito faz sintoma, o modo de gozar do seu inconsciente. Afirmar que o sintoma é um even- 
to do real significa dizer que ele "é o efeito de um enunciado impossível de dizer" (GERBASE, 2010, pp.139-140). E é mesmo por isso que a psicanálise é a clínica do real, o que levou Lacan a afirmar que o que foi feito pela fala deve ser desfeito pela fala (LACAN, 1977/2000). Mas como demonstrar a eficácia analítica se ela é uma prática de linguagem que opera com os equívocos do significante?

Como demonstrar a eficácia de uma análise cuja ética é a "práxis de sua teoria”, teoria que não pode ser tomada como modelo e uma práxis que se produz à medida das ocorrências? Lacan sempre esteve atento aos efeitos terapêuticos e didáticos produzidos em uma análise. Por isso, em 1967, ele propôs o passe, um dispositivo capaz de recolher esses efeitos, ali onde o analisante pode dar testemunho dos problemas cruciais da psicanálise (LACAN, 1966a/2003, p. 249).

\section{MBE x PBEx}

A clínica psicanalítica não se baseia em evidências da realidade, mas na ex-sistência do real. E se o real é o impossível, sua eficácia não pode ser aferida pelos critérios da MBE, incapazes de avaliar a mudança na posição de gozo que o falasser ocupa no Outro, ao sair da impotência à impossibilidade e fazer do sintoma uma invenção. Entretanto, ainda que a MBE almeje unificar e padronizar o conhecimento para transmiti-lo, e que a psicanálise não permita tal objetividade, Lacan não deixou de se preocupar com a transmissão.

Na Proposição de 9 de outubro de 1967 sobre o psicanalista da Escola, Lacan apresentou o dispositivo do passe, com o objetivo de interrogar a análise do analista, de pôr à prova o fim de uma análise por meio da passagem de analisante a analista e as consequências do ato, pela emergência do desejo do analista. Em 1976, ele (LACAN, 1976/2003, p. 568) acrescentou ao passe um meio de "pôr à prova a historização da análise”. E no passe, historizar-se “de si mesmo", como esclareceu Soler em Conferência no Brasil (SOLER, 2016), é historizar não a própria vida, mas a própria análise, isto é, historizar o processo analítico.

Por isso, a Escola proposta por Lacan seria o lugar capaz de "sustentar o desejo que é preciso para resistir às seduções adversas do discurso contemporâneo e manter [...] as finalidades próprias da psicanálise” (SOLER, 2012, p. 220). Lugar do analista pôr à prova, junto à comunidade analítica, como ele "orienta a direção da cura, enquanto contribui para a elaboração contínua dos conceitos” (FINGERMANN, 2016, p. 58), contribuindo para o saber, sem o que, segundo Lacan, (1973b/2003, p. 314) "não há chance de que a análise continue a dar dividendos ao mercado". Por esta razão, Fingermann (2017) propõe "enfrentar com ética e tática a ciência e o capital que pretende obsoletar a psicanálise".

Mas por que Lacan foi tão criterioso ao criar o dispositivo do passe, com uma série que inclui passantes, passadores, cartel do passe, AMEs? Pode-se pensar que a criação 
do dispositivo do passe seria não somente uma resposta de Lacan à IPA, mas uma estratégia para fazer frente a uma lógica biopositivista que estava por vir? Seria o passe a evidência da psicanálise? Que evidências esse dispositivo pode dar e a quem?

Para um campo ser ciência, ele precisa ter um método, um campo teórico e um objeto. A psicanálise dispõe de teoria e método que já duram mais de um século. A ciência positivista não alcança a psicanálise, porque ela não pode ser verificada objetivamente, por ser uma ciência do particular. E, mais do que uma ciência, a psicanálise é uma experiência. Se a psicanálise é ciência, é uma ciência do real e o passe, um dispositivo que evidencia a ciência do real, da ex-sistência.

Lacan (1965/1998, p. 891) acreditava que o primeiro obstáculo à comprovação do valor científico da psicanálise devia-se ao fato de a comunicação dos seus resultados ficar restrita ao setting analítico ou, com a criação de sua Escola, à comunidade de analistas. Na ciência, ao contrário, o saber é comunicado, porém, a forma lógica atribuída a esse saber termina por suturar o sujeito nele implicado.

Considerando que o testemunho do passe seja uma forma de comunicar os resultados e o processo de uma análise, o dispositivo do passe poderia ser um meio de superar esse obstáculo. Entretanto, por mais criterioso que seja esse dispositivo, seria ele capaz de tornar as ideias psicanalíticas evidentes fora dessa comunidade? Evidência é indício, traço, sinal, prova, fundamento, comprovação, demonstração de que ali houve uma análise. Como comprovar a eficácia de uma experiência a partir de um dispositivo que visa verificar o real, o equívoco, a letra de gozo, o sem-sentido, a não ser por aqueles que passaram por ela? Se o passe é uma evidência da psicanálise, seria uma evidência restrita à comunidade de analistas. E se assim for, seria isto um problema crucial para a psicanálise na contemporaneidade?

\section{Referências bibliográficas}

FINGERMANN, D. A (de)formação do analista - As condições do ato psicanalítico. São Paulo: Escuta, 2016.

Conferência: A (de)formação do analista - As condições do ato psicanalítico. Em Debate de Análise, Campo Psicanalítico de Salvador, 2017. Inédito.

FREUD, S. (1895) Projeto para uma psicologia científica. In: Obras Psicológicas Completas de Sigmund Freud. Rio de Janeiro: Imago, 1996. v. 1.

. (1933) A questão de uma Weltanschaung. In: Obras Psicológicas Com-

pletas de Sigmund Freud. Rio de Janeiro: Imago, 1996, v. 12

. (1940) Esboço de psicanálise. In: Obras Psicológicas Completas de Sig-

mund Freud. Rio de Janeiro: Imago, 1996, v. 23

GERBASE, J. Os paradigmas da psicanálise. Salvador: Associação Científica Campo Psicanalítico, 2008, pp. 9-83. 
. Entrevista de Ida Freitas com Jairo Gerbase. Stylus: Revista de Psicanálise. Rio de Janeiro: Escola de Psicanálise dos Fóruns do Campo Lacaniano, n. 20, 2010, pp. 139-145.

. A hipótese de Lacan. Salvador: Associação Científica Campo Psicanalítico, 2011, p. 19.

LACAN, J. (1965) A ciência e a verdade. In: Escritos. Rio de Janeiro: Jorge Zahar Ed., 1998.

. (1966a) Problemas cruciais da psicanálise. In: Outros escritos. Rio de Janeiro: Jorge Zahar Ed., 2003.

. (1966b) Respostas a estudantes de filosofia. In: Outros escritos. Rio de Janeiro: Jorge Zahar Ed., 2003.

(1966c) Pequeno discurso no ORTF (Office de Radiodiffusion Television Française). In: Outros escritos. Rio de Janeiro: Jorge Zahar Ed., 2003.

. (1967) Proposição de 9 de outubro de 1967 sobre o psicanalista da Escola. In: Outros escritos. Rio de Janeiro: Jorge Zahar Ed., 2003.

. (1972) O aturdito. In: Outros escritos. Rio de Janeiro: Jorge Zahar Ed., 2003.

. (1973-74) O seminário, livro 21: os não todos vagueiam. Salvador: Publicação não comercial do Espaço Mœbius, 2016.

. (1973a) Televisão. In: Outros escritos. Rio de Janeiro: Jorge Zahar Ed., 2003.

. (1973b) Nota Italiana. In: Outros escritos. Rio de Janeiro: Jorge Zahar Ed., 2003.

. (1974a) A Terceira. Cadernos Lacan, volume 2. Porto Alegre: Publicação interna da Associação Psicanalítica de Porto Alegre, 2002.

. (1974b) Entrevista a Emilio Granzotto para a Revista Panorama. Magazine Litéraire, 2004. Disponível em: http://www.campopsicanalitico.com. br/media/1072/entrevista-1974-magazine-litteraire.pdf. Acesso em: 11 junho 2016.

. (1976) Prefácio à edição inglesa do Seminário 11. In: Outros escritos. Rio de Janeiro: Jorge Zahar Ed., 2003.

. (1976-77) O seminário, livro 24: l'insu-que-sait de l'une-bévue s'aile a mourre. Aula de 11/01/1977. Disponível em: http://www.campopsicanalitico. com.br/media/1068/efeitos-de-significantes.pdf. Acesso em: 11 junho 2016.

. (1977-78). O seminário, livro 25: o momento de concluir. Aula de 15/11/1977. Disponível em: http://www.campopsicanalitico.com.br/ media/1044/a-tagarelice-comentario.pdf. Acesso em: 11 junho 2017.

MEZAN, R. Que tipo de ciência é, afinal, a Psicanálise? Nat. hum., São Paulo, v. 9, n. 2, pp. 319-59, dez. 2007. Disponível em: http://pepsic.bvsalud.org/scielo. 
php?script=sci_arttext $\&$ pid $=$ S1517-24302007000200005\&lng=pt $\&$ nrm $=$ iso. Acesso em: 24 maio 2016.

NOVAES, H. M. D. Incorporação e utilização de tecnologias: a boa prática médica. Médico. HC-FMUSP, v. 2, n. 7, 1999, pp. 19-21.

SOLER, C. A oferta do passe. Wunsch 7, 2008, pp. 19-22. Disponível em: http:// www.champlacanien.net/public/docu/4/wunsch7.pdf. Acesso em: 19 outubro 2016.

O sujeito, o inconsciente e o tempo. Entrevista realizada por Dominique Fingermann e Maria Rita Kehl. A Peste: Revista de Psicanálise e Sociedade, São Paulo, 2009, v. 1, n. 1, pp. 185-194.

Disponível em: https://revistas.pucsp.br/index.php/apeste/article/viewFile/2707/1750. Acesso em: 13 outubro 2016.

. O inconsciente reinventado. Rio de Janeiro: Cia de Freud, 2012.

Conferência: A nova economia do narcisismo. XVII Encontro Nacional da EPFCL -Brasil. São Paulo, 2016.

\section{Medicina baseada em evidência x psicanálise baseada na ex-sistência Evidence-based medicine x psychoanalysis based on ex-sistence}

\section{resumo}

O modelo biotecnicista da medicina contemporânea adota como critério a eficácia do tratamento, regra fundamentada na medicina baseada em evidências (MBE). A eficácia terapêutica é determinada pelas leis de mercado, norteadas pelo discurso capitalista, e a psicanálise não escapa dos seus efeitos. Se a eficácia é medida por critérios objetivos, replicáveis e transmissíveis, a psicanálise vem sofrendo violentas críticas, acusada de ser ineficaz e de produzir resultados carentes de evidências. Este artigo tem como objetivo esclarecer que a psicanálise não é uma clínica baseada nas evidências da realidade, mas na ex-sistência do real. E se real é o impossível, sua eficácia não pode ser aferida pelos critérios da MBE. Como comprovar a eficácia de uma experiência a partir de um dispositivo que visa verificar o real, o equívoco, a letra de gozo, o sem-sentido, a não ser por aqueles que passaram por ela? Seria o dispositivo do passe a evidência da psicanálise?

\section{palavras-chave:}

Psicanálise; medicina baseada em evidências (MBE); ex-sistência; dispositivo do passe. 


\section{abstract}

The biotechnical model of contemporary medicine adopts as criterion the effectiveness of the treatment, based on evidence-based medicine (EBM). Therapeutic efficacy is determined by market laws, guided by the capitalist discourse, and psychoanalysis does not escape its effects. If efficacy is measured by objective, replicable and transmissible criteria, psychoanalysis has come under severe criticism, accused of being ineffective and producing results that lack evidence. This article aims to clarify that psychoanalysis is not a clinical practice based on the evidences of reality, but on the ex-existence of the real. And if the real is the impossible, its effectiveness cannot be measured by the EBM criteria. How to prove the efficacy of an experience from a procedure that seeks to verify the real, the misconception, the letter of jouissance, the nonsense, if not by those who have been through it? Is the institutional procedure of the Pass the evidence of psychoanalysis?

\section{keywords:}

Psychoanalysis; evidence-based medicine (EBM); ex-existence; procedure of the pass.

\section{Recebido:}

$24 / 05 / 2017$

\section{Aprovado:}

06/06/2017 